\title{
Scape of Vulnerability and Resilience in Viramma, life of an untouchable
}

\author{
Jebamalar. E \\ Research Scholar, Dept. of English, Pondicherry University, \\ jeba.litmsw@gmail.com , ORCID id: oooo-ooo1-8468-9535
}

\begin{abstract}
Viramma, Life of an Untouchable (1997) is a telling of Viramma's own life recorded in print wherein her life's response to different forms of vulnerabilities was one of resistance which revealed resilience. Belonging to an economically disadvantaged, and socially marginalized community, Viramma's narrative reached far across seas only with the support received from the purposive use of the tool of translation aided by transcripts collected from ethnomusicological research (1997, p. v). The objective of the paper is to analyse the variables of vulnerability and resilience in the life narrative of Viramma viewed through the lens of sustainable livelihood framework. Situated within the life narrative of Viramma are a number of themes which give rise to significant queries in relation to vulnerability induced due to circumstances. It is from analysis of instances from within Viramma's life with the theoretical backing of Brene Brown's shame resilience theory, this research paper seeks to find an answer to the query, if Viramma's response to vulnerability challenged or reinforced gendered subjectivities?
\end{abstract}

Keywords: life writing/narrative, vulnerability, resilience, responses, sustainable livelihood framework, shame resilience theory.

\section{Introduction}

Essentialist understandings of gender identifies women and children among the vulnerable (Carpenter, 2005). Encapsulated within such an understanding is the assumption that women, children and the elderly need support because they can't fend for themselves. This argument is the premise that is contested in this article, with the help of investigation that is aided by use of the indicators derived from the sustainable livelihood framework and Brene Brown's shame resilience theory. The autobiography of Viramma, which is self-referential in nature, is put to a litmus test, in order to find the truth value of the assumed claim that groups women among the vulnerable.

Viramma, Life of an Untouchable (1997) is a collaborative autobiography by Viramma, Josaine Racine and Jean-Luc Racine that was born out of an ethnomusicological research of Josaine Racine. The narrative which was originally recorded in Tamil, was translated into French and first published in the language in 1995. This article benefits from the English translation of the autobiography by Will Hobson.

(c) AesthetixMS 2019. This Open Access article is published under a Creative Commons Attribution Non-Commercial 4.0 International License (http://creativecommons.org/licenses/by-nc/4.o/), which permits non-commercial re-use, distribution, and reproduction in any medium, provided the original work is properly cited. For citation use the DOI. For commercial re-use, please contact editor@rupkatha.com. 
Viramma's narrative is one example of how life writing of women in India, has offered the readers a first-hand glimpse of the lived realities of women as told by themselves. For a long time in the skein of themes that was addressed in the history of Indian women's writing, women from the affluent section of society, dominated the literary scene, with their privilege, and access to the publishing world. At this point of time only the established, accomplished and forward looking, elite minority with access to education took pen to express their lives through the form of autobiographical telling ${ }^{1}$. Wherein a majority of them who did not belong to the elite minority were left behind or took to their mother tongue to express themselves. At the close of the twentieth century, women whose lack of literacy denied them an opportunity to be heard also found a voice as ethnographic research and life stories gained popularity. Narratives of the likes of Phoolan Devi, the bandit queen and Viramma found a voice through this form of narrative record of telling. Although incipient in nature, the increase in popularity of life writing gave more visibility to women living in the fringes of the society. Women who live in the margins have scored dismally in most indicators of well-being and are automated to be vulnerable at different levels ${ }^{2}$.

Since vulnerability is a term that is mostly used and confined to the discourse related to disaster studies, the use of the term within the frame of a life narrative ${ }^{3}$ needs an exhaustive analysis that will examine the many unexamined assumptions. Vulnerability, in the context of disaster prevention and mitigation categorizes 'women and children' among the vulnerable who need aid to move to safety. Despite tangential references to the vulnerability of women in life narratives, a detailed analysis has failed to make a presence within the literary discourse. This article seeks to bridge this gap through its analysis with use of significant elements borrowed from the sustainable livelihoods framework. Viramma's life has reams of experiences which can be comprehended in an effective way through structured probing. In order to avoid untenable propositions, a need for framework arose so that the analysis is structured and reliable.

\section{Brief scape of Viramma's life}

Viramma, was born into a family of agricultural labourers who worked for generations in a farm owned by an upper caste, Reddi. There were several dents in the rubric of Viramma's life that forced her to become vulnerable. These dents include her being born into the 'pariah' community (Viramma, Racine \& Racine, 1997, p.165) which she prefers to address as 'untouchable', her being a women, whose sex was not a welcome sign for prosperity in her community (Viramma, Racine \& Racine, 1997, p.3), her belonging to a class that suffered social disadvantage for her family owned no land (Viramma, Racine \& Racine, 1997, p.156) and depended on subsistence agriculture for survival (Viramma, Racine \& Racine, 1997, p.2). Together, this pushed Viramma to the margins of disadvantage and therefore she suffered vulnerability in terms of caste, sex and class.

There are still several other instances on how vulnerability cast its deadly fangs on Viramma's life. Victimized as a result of caste, Viramma became the tale bearer of the ghastly plight of her community. Members of her caste are denied the right to dignity for "a Pariah had no rights in those days; he'd lie flat on his stomach in front of his masters" (Viramma, Racine \& Racine, 1997, p.53). Coupled to being denied basic rights collectively as a community, her individual right of choice or free will are also in crisis for she is married as a child to a man much older than her. She vents her doubts and thoughts on early marriage as

At that age you don't understand what marriage is. I was going to be parted from the people I loved: as far I could see, it was like a kidnapping. When we were small, we were 
told to watch out for kidnappers and now, here I was going to be as good as kidnapped with my whole family's blessing! They aren't going to kill me but make me work and 'make a woman out of me'. (Viramma, Racine, \& Racine, 1997, p.17).

Viramma has not exercise her free-will during her childhood for "choice is a process of growth, of progressive mental organization through selection and assimilation of the materials which life presents" (Cooley, 1902, p.20). There is no trace of agency that Viramma asserts during the early childhood and adolescence phrase of life, facing the events as they came by.

Although Viramma's demeanour is not constituted by plenitude of the wealthy (Viramma, Racine \& Racine, 1997, p.52), her strength is rooted from within her inner self that finds expressions through her response to circumstances. Characteristically as she grows older, Viramma turns to be preeminent for her resilience, despite the precarious nature of her livelihood. The uneven distribution of power among the caste groups leaves her at a disadvantage. Her survival which is centred around dependency gradually withers its hold when she begins to work as a midwife, offering her service to her community. This transition accounts for a shift in her approach to living which earlier relied on the mercy of her employers whose caste perpetuated oppression denied her community's basic rights. While she gives less room for the welt received out of inhumane treatment from the hands of her masters to die away, still continues to exercise her new found liberty in gaining part-time employment that is independent of serfdom, which was in practice for generations (Viramma, Racine \& Racine, 1997, p.66). Viramma's resilience came not as a seismic shock to the system in place. Rather it came by means of refuting in proportions that would sent jitters in ways that is not easily visible. Her gradual rise to strength, redefining the circumstantial crisis by not succumbing to the system makes Viramma, a survivor despite all.

\section{Livelihood indices and narrated life}

Livelihood in general is identified as that which serves as a source of income and as a means of living. There are diverse livelihood options that individuals pursue in order to survive. The impact of livelihood on one's cycle of life is phenomenal. The pursuit of livelihood differs according to the setting. Both rural and urban settings influence the types of livelihood and practices. There is inherent power dynamics that operate in the shaping of livelihood for it must be noted that "Livelihood activities are not neutral. They engender processes of inclusion and exclusion" (Haan, 2012, p.349). The narrative of Viramma clearly hints at how in enforcing caste, the livelihood of her community has become one that is destined to serve the upper caste, Reddi's. Viramma has not much option left to make a living but just to follow, that which is in practice for generations. Hinting at this exclusionary tact, that has enforced separate strictures on discrete job roles that are assigned to each community, Viramma narrates on how she and the work she does is looked down on, as an object of insignificance: "a new Pariah in the ceri -nobody's interested in that, as you can imagine. But at the grand Reddi's they knew I was Mannikam's wife. I used to go there with my mother-in-law to sweep out the stable and collect cow dung. My family-in-law have been serfs at the Reddi's for generations." (Viramma, Racine, \& Racine, 1997, p. 51). While there are a number of other instances of discrimination recorded in the narrative, in order to understand vulnerability it becomes necessary to view each of the narrative contexts and events systematically. Given that "knowing a socially constructed world is knowing it from within" (Smith, 2004, p.28), this paper capitalizes on the life narrative's potential to unravel themes by use 
of a borrowed framework that is quintessentially representative of livelihood in relation to lived lives.

The Sustainable Livelihood Framework (see. Figure 1) that is put to use in this paper is borrowed from sustainable Livelihood Guidance Sheets prepared by the DFID (Department of International Development), United Kingdom.

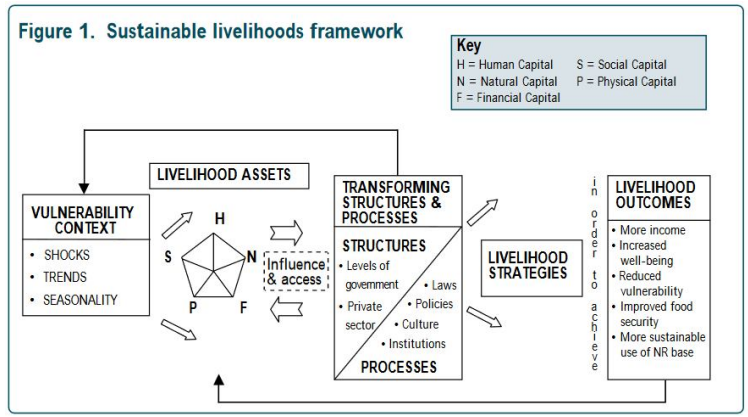

Figure 1: Sustainable livelihood framework Source: DFID, 1999.

Although the above framework cannot be used in entirety in the context of the life narrative of Viramma thrust is on select elements from within the framework. Livelihood assets and vulnerability contexts is dissected from the framework so to create a tailor made design (see. Figure 2) for enumeration of lived life.

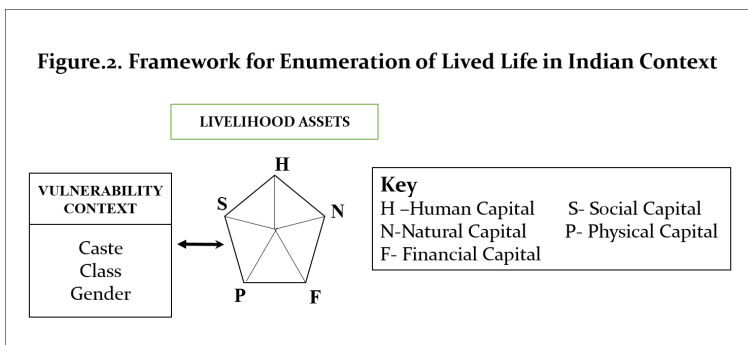

Figure 2: Framework for Enumeration of Lived Life in Indian Context

This framework was designed to suit the purpose of enumeration of lived life in Indian context. In most cases the key players that influence the vulnerability context include: caste, class and gender. It is only when the vulnerability context is studied in relation to livelihood assets that any lived life can be deciphered. The livelihood assets (see. Figure 2) that are represented in form of the pentagon is inclusive of human, social, natural, financial and physical capital. The distance between the centre and the margin for each capital is the signifier for the shape of the pentagon distorts from original when access to each capital either decreases or increases. The interplay between vulnerability context and livelihood assets either increases or decreases livelihood outcome.

The overall purpose is to gain an analytical understanding of Viramma's life within the context of livelihood in order to comprehend her life's interaction with vulnerability and resilience. The section below first draws on different livelihood assets each discussed separately and later within the vulnerability contexts and resilient interfaces. 


\subsection{Human capital}

In the Sustainable Livelihood Guidance sheets, human capital at "a household level is the amount and quality of labour available; this varies according to household size, skill levels etc." (DFID, 1999, pp. 2.3.1). Viramma is fortunate to have the benefit of human capital for her family size is big. Each of her family members have worked as labourer in the upper caste, Reddi's farm. Viramma provides details of how the man power within the household is put to productive use for:

All my family is employed at the Grand Reddiar's. My husband takes care of the pumps. The Reddiar owns two which irrigate every day. I collect cow dung and clean the stable. My daughter Miniyamma helped me until she got married. Sundari has done the same and now it's my daughter-in-law Amsa who works at the Reddiar's. Anban started looking after the cows. Now he does the important cultivation work with my husband. (Viramma, Racine, \& Racine, 1997, p.156)

Viramma's childhood was no different for she belonged to a household that was equally big. The human capital indices of Viramma rank to her to be rich and stable.

\subsection{Natural capital}

Individual assets such as land holding, livestock etc. come under the preview of natural capital. (DFID, 1999, pp. 2.3.3). Although the human capital indicators are positive, in the analysis of natural capital Viramma fails to make any gain. Because Viramma is also hardwired into believing that: "just as there are rich high castes, so there are the poor low castes. God gave the land to the rich high castes and he gave the poor low castes the duty of cultivating the land. The duty of the rich high castes is to employ us" (Viramma, Racine, \& Racine, 1997, p.160). While Viramma's grandfather owned some land, Viramma husband or family owned none. (Viramma, Racine \& Racine, 1997, p.156). Viramma's mention that she requested land for rent for cultivation reveals that although she owned no land, she owned cattle which she desires to rear in the rented plot of land. (Viramma, Racine, \& Racine, 1997, p.155). The livestock she owns is the only natural capital that comes directly under her holding.

The downside to lack of resources in the form of natural capital is the need to depend on other sources than one's own for survival. This increases the probability of the individual to survive through pursuit of precarious livelihood options. Viramma was secure despite her failing to score dividends in her share of owning assets that belong to the natural capital. This is only because of generational agricultural labour and trade off with the Reddi's. Incidentally it is here that despite being discriminated against Viramma gets her supplies without any delay.

\subsection{Financial capital}

As the name suggests the financial capital signifies the income from sources that are one's own or that of others and management of them ((DFID, 1999, pp. 2.3.5). In case of Viramma, she was guarded against shocks and threats of low financial security because of serfdom which she acknowledges as:

By working hard at the Reddiar's we've been able to lead our lives in the proper way. We've been able to give Miniyamma and Sundari away in marriage with silver ankle chains and some clothes. We've paid our share of funeral expenses when we've had to. I've been able to buy these jewels for my ears. And when we married Anban, the Reddiar gave Amsa 
her gold tali and her sari. Thanks to the Reddiar, thanks to his fortune -and it's a great one, especially in land -we have enough to eat without worrying...The serfs who work at the Reddiar's have their rice guaranteed! (Viramma, Racine \& Racine, 1997, p.156)

Although Viramma's life has adequate financial security, the notion of savings does not figure in any portion of her disclosure of life's events. This leaves the financial capital plank on an uneven field for any external threat can disturb the accustomed normalcy to life.

\subsection{Social capital}

Social capital is acquired on the basis of an individual's ability to establish "network and connectedness" (DFID, 1999, pp. 2.3.2). Viramma had earned the respect of the members within her community. She is a trusted and sought after voice at times of crisis. Viramma as the midwife of the people of ceri ${ }^{4}$ describes her experiences and social connectedness she shares with her people "a nurse comes to the village...she records the name of all the pregnant women all those who've given birth recently, then she comes to the ceri. I'm the midwife here and in the same way I take her to all the women who haven't had a bath or who are in labour...when a woman goes to labour, they come and find me" (Viramma, Racine \& Racine, 1997, p. 66). According to Bhandari and Yasunobu social capital is a "collective asset in the form of social relations, shared norms, and trust that facilitate cooperation and collective action for mutual benefits". Social capital "can be grouped into three broad categories: social networks (of families, friends, communities and voluntary associations), norms of reciprocity (shared norms, values and behaviours), and trust (in other people and institutions)" (Bhandari, \& Yasunobu, 2009, p.491). When it comes to establishing connections and accumulation of social capital assets, Viramma stood first, and lacked not. It must be noted that this hold on social capital of Viramma was confined only to the ceri. While in the $u r^{5}$, where she was discriminated for her caste, she suffered neglect and was not received with equal reception.

\subsection{Physical capital}

Infrastructure and access to services provided through government and institutions all define the contents of the physical capital ((DFID, 1999, pp. 2.3.4). In the life narrative, there are very little avenues to know this aspect of asset. The changing feature of acceptance of her community and inclusiveness that is envisioned and executed by the government mechanism gives a positive affirmation to Viramma's inner strength. She recounts the transformations that has come to be in ways big and small as

And have you noticed the changes at school? There are three or four teachers now. They say that two of them are Harijans. Of course they're not Pariahs from Karanai, but they live next to the school in the ur. And do you know where the two families of pig rearers have been given a place to live? Behind the lotus pond, near the potter's! You remember that empty land behind the Reddi quarter? Well, it's there right in the heart of the ur! The government ordered it and no one in the ur argued. One of the pig-keepers doesn't raise animals any more, he's an agricultural worker like us. (Viramma, Racine \& Racine, 1997, p.124)

Viramma hints in passing, of how critical she feels about being treated with lack of dignity by the medical personnel while offering family planning and other health care services to the women in the ceri. She mentions that the attitude of the medical personnel is suggestive of 'insult'.

(Viramma, Racine \& Racine, 1997, p.57). Despite the government's efforts to create inclusive structures, discrimination continues to be. 


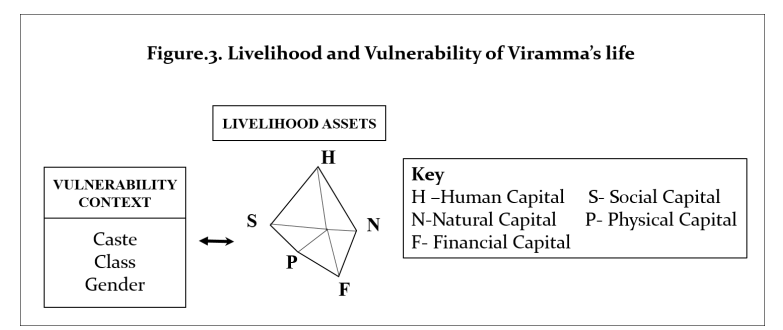

Figure 3: Livelihood and Vulnerability of Viramma's Life

In sum (see. Figure 3), Viramma has a reasonable grip over assets in the form of human capital and social capital. While her financial assets temporarily declare her to be stable, her natural capital and physical capital indices are in an imperil state. The subsequent section will deal with the livelihood asset of Viramma as it vacillates between vulnerability and resilience.

\section{Vulnerability Contexts}

"Lives are lived at the intersection of individual and social dynamics" (Maynes, Pierce, \& Laslett, 2008, p.2). Viramma's life and livelihood is built around the overarching themes of exclusion, discrimination and exploitation. Hooked into her life's experience are a cluster of issues that point towards the excesses of inequality. Choosing to name this lived experience as ingrained in vulnerability, is on the presumption that Viramma herself was vulnerable. The term vulnerability for the purposes of analysis can be defined as

An individual is vulnerable when he or she is in a position that threatens his or her ability to develop and achieve the most fundamental dimensions of well-being. Vulnerability can be caused or exacerbated by both internal and external variables including, but not limited to, an individual's mental state, economic independence, political standing, physical security or physical health. (Guidry-Grimes \& Victor, 2012, p.131)

Vulnerability derives from the Latin word vulnus or 'wound'. (Turner, 2006, p.28). There are a number of scars in Viramma's life from the wound by caste, class and gender discrimination.

Caste is found to act as an oppressive trope enmeshed throughout Viramma's life and can be traced to be omnipresent in most occurrences within the life narrative. Menon indirectly makes a pointed reference to women who have less scope to make a choice over the crucial decisions that are related to their lives to be probable "victims" (Menon, 2012, p.175). Placing this viewpoint as a frame of reference to narrated life it can be inferred that right from her birth into an oppressed pariah caste, there are several occurrences beyond Viramma's control which curb her agency or right to choice and enable exploitation. It is generally perceived that for any decision making process the role that choice plays is vital. Viramma's life choices is less her own. "Choice is like a river; it broadens as it comes down through history -though there are always banks -and the wider it becomes the more persons drown in it. Stronger and stronger swimming is required, and types of character that lack vigor and self-reliance are more and more likely to go under" (Cooley, 1902, p.39). The livelihood she pursued as an agricultural labour was also predestined for she had less way out of the serfdom under whose control her community lived for years (Viramma, Racine, \& Racine, 1997, p.51). In a nascent analysis of interaction of caste, class and gender, Velaskar discusses in detail the differential equations that women from different social hierarchy share 
Within caste, women share, albeit unequally, the pure and impure natural substance associated with caste bodies. At one level, caste accords inferior status to all women, yet at another level as 'caste woman', religio-cultural power and social status are distributed to women. As per caste norms, honour is differential and graded between caste groups. Brahmin women partake the so-called 'purest' substance and are assigned critical roles in the social practice of cultural superiority and preservation of caste. Women in other caste categories are similarly assigned 'caste dharmas'. A woman is goddess when complaint to the caste-gender order and a demon when not. (Velaskar, 2016, p.405)

The social norms of do's and don'ts is strictly enforced on Viramma through social sanctions that reinforced practices associated with retaining the divide brought by the practice of caste hierarchy. Any transgression by means of flouting the system that's already in place was counted unacceptable.

Viramma's life choices is strangled by normative prescriptions that was reinforced through gendered construal. Menon tries to enlist the probable causative factors that restrict the choice of women "...because 'freedom of choice' is always exercised within strict boundaries that are nonnegotiable -these boundaries are defined by economic class, by race and caste and of course gender. The freedom to choose is never absolute" (Menon, 2012, p.175). Viramma's narrative brings forth the underside of what it takes for a women to suffer from multiple oppression that is caused due to marginal status in terms of sex, class and caste. Denuded of the right to access the common property resources in the village because of caste divide, the family and community to which Viramma belonged are discriminated against. The territorial segregation of boundaries between the upper caste and that of the lower caste residents is a case in the point. The ur, is the fortified residence of the upper castes, situated in the heart of the village while ceri, located at the outskirts of the village is where individuals belonging to the lower caste reside. The residents of each caste live in discretely demarcated spaces that are territorially separate from each other. The only connect between the residents of ceri and ur finds a detailed reference in the telling of Viramma as: "who'd look after their cows, if it wasn't for our children? Who'd cultivate their land, if it wasn't for us? ...We still live in the ceri. We've got our customs, our ways, our own life, we're better off amongst ourselves, but we're not completely cut off from the ur outside of work." (Viramma, Racine \& Racine, 1997, p.191). The exchange of labour for goods was the only connect that bridged the residents of ceri with the residents of ur. As for Viramma, the practice of serfdom to which both her paternal, maternal and in-laws home was bonded, perpetuated oppression in the guise of secure livelihood and prosperity. The notion of purity and pollution between the communities is also in practice. The reason that Viramma attributes to this continual practice of aseptic nature is expressive of her belief: "But meat is unclean, it's waste. Milk is pure. And as we eat waste, we're unclean” (Viramma, Racine \& Racine, 1997, p.160).

Viramma questions the fake morality of the upper caste residents of ur to whom the residents of ceri are unclean. Ironically, the breast milk of women from ceri is much sought after to feed the children of ur (Viramma, Racine \& Racine, 1997, p.75). Recollecting an instance of pain, Viramma narrates how she was denied a glass of water from the upper caste reddiar's son whom she had breast fed as a child. The contempt with which she was looked at by the now grown up adult "he doesn't respect me and if I'm at his house, in the courtyard, he says to me, 'Aye! Stop there, you! It smells of Pariah here!'...He'd drunk at my breasts, and now here he is, thinking twice about giving me a little water!" (Viramma, Racine \& Racine, 1997, p.76). This instance is an exemplar that is descriptive of Viramma's experiences of exclusion suffered on the basis of caste. 
As a woman who belonged to the lower caste, with no stable livelihood support Viramma suffered gender, caste and class based discrimination. Although women faced gender oppression in general, the power equation between the women from the ceri and ur was not the same. While women from the ceri had less power over themselves and others, the women from ur had greater power with which they dominated the women from the ceri. Viraamma narrates an occurrence in which a civil servant harassed her. The incident was dismissed off and no action taken. But when the same strait was met by a woman from the ur it was responded with the transfer of the civil servant with immediate effect. (Viramma, Racine \& Racine, 1997, p.54). Barring the women from the $u r$, to Viramma and her community these repercussions of gender, caste imbalances gave forth a jaundiced negotiation of life experiences. The natural resources in Viramma's village is unevenly distributed too because unequal caste equations and power relations. While serfdom continues to be in practice, the owners of the land are the upper caste, Reddi while individuals from Viramma's community are engaged in labouring the fields of the powerful owners of the land.

Women in India are also discriminated through practices that are part of the patriarchal system. Through marriage, women are uprooted from their parental homes to their wedded home. This system which is a continuing practice in patriarchal societies can be identified as "patriarchal virilocality isolating women from all previous support systems, and leaving them entirely at the mercy of their husband's families" (Menon, 2012, p.32). On her mother's passing Viramma put into words as how it felt to lose contact with maternal home for "it's never the same after your mother dies, you're never received in the same way. The village I grew up in has almost become foreign to me now, even though my brother still lives there" (Viramma, Racine \& Racine, 1997, p.131). When support systems fail women are in turn vulnerable.

While some researchers are of the view that vulnerability is an inherent attribute of a woman, Ahmed points to the reverse of this claim that suggests "vulnerability is not an inherent characteristic of women's bodies; rather, it is an effect that works to secure femininity as a delimitation of movement in the public, and over-inhabitance in the private." (Ahmed, 2004, p.7o). When Viramma's life is viewed in this context, she was no different from other women who reside in the $u r$, because irrespective of their caste the women had to strictly conform to norms that imposed severe restrictions on their mobility. Patriarchal norms governed both women's mobility as well as controlled their decision making. The stark contrast with Viramma is the imposition of the notion of purity and pollution through which her mobility was restricted even more while the women from the ur enjoyed their privileges. There are differing views expressed in postulations on vulnerability. One of the conceptualisation endorsed the universal claim to vulnerability and reduced vulnerability to be a basic human condition declaring both men and women to be vulnerable (Turner, 2006).

Although the above explored view points on vulnerability can be agreed on, it can't be denied that the degree of vulnerability varies from one individual to another. In Viramma's case it is pertinent to borrow the idea of "compounded vulnerabilities" (Guidry-Grimes \& Victor, 2012) for her tryst with vulnerability cannot be cast aside to be a monolithic issue. Vulnerability to Viramma is "multidimensional and they point to a number of interconnected threats to one's well-being" (Guidry-Grimes \& Victor, 2012, p.127). The elaboration on 'compounded vulnerabilities' befits the purpose of description of the events that occurred in the life span of Viramma for

Compounded vulnerabilities arise when systematic or institutional conditions intersect in a manner that creates additional barriers to the agent's ability to develop or achieve well- 
being. Historically disadvantaged populations are particularly susceptible to being kept in disadvantaged positions when an institutional standard or condition plays into, reinforces and perpetuates the stigma of the population stereotype (Guidry-Grimes \& Victor, 2012, p.136).

Close to an appeal to recognize "compounded vulnerabilities" is the acknowledgement of the relational nature through which vulnerability manifests itself. Given these takes on vulnerabilities, Luna seeks to question the rigidity that connate all women with vulnerability instead advocates a need to acknowledge the "layers of vulnerability" for

The metaphor of a layer gives the idea of something "softer," something that might be multiple and different, and that may be removed from layer by layer. It is not "a solid and unique vulnerability" that exhausts the category; there might be different vulnerabilities, different layers of opening. These layers may overlap (Luna, 2009, p.128)

Going by this line of thought, not all women who figure within the narrative of Viramma is vulnerable. While Viramma was vulnerable, some were not. Despite all asymmetries that push Viramma to vulnerability, her response to the social and economic vulnerability of her circumstances was one of difference. This aspect will be looked at critically in the context of vulnerabilities interface with resilience.

\section{Resilience Interfaces}

There are several responses to vulnerability and resilience is just one of them. The variable of resilience in relation to vulnerability in Viramma's life can be described as that which enabled her life to stay "intact but at risk, in the same way a fine piece of porcelain is unembellished but highly vulnerable to being damaged" (Kottow, 2003, p.464). Vulnerability can be treated to be in close concurrence to resilience. Resilience in turn can be treated one response to vulnerability. The sketchy picture of Viramma captured from the vignettes of lives episodes reveal her to be moving either upstream or downstream but never forgetting to exercise agency. There are number of instances where her agentic responses have enabled resilience.

Viramma assimilated caste oppression that was thrust on her as her own, failing to redraw the boundaries as new. She admits her caste status and willingly affiliated herself, with her caste bound identity, as a 'pariah'. Her agency is restricted within her community where she asserts her voice in all ways but distances herself with interfering in matters of caste. The narrative of Viramma "is not in primary sense, a text attacking oppression, but it is a text which tells how an oppressed woman lives and thinks" (Racine \& Racine, 1997, p. 310). In other words to Viramma the caste frame is untouched and the other elements of the narrative and the happening of life events all occur within the frame of caste, whose boundary is rigid and accepted to be normal.

There are several emotions that become apparent from the vulnerability context in Viramma's life. Caste subjection eventually brings shame to the self that adorns its label. Brown while elaborating on the relatedness of the emotion of shame that either thwart or nurture resilience describes its nature as "shame resilience is best understood on a continuum that represents, on one end...feeling trapped, powerless, and isolated. Located at the opposite end of the continuum are...components of shame resilience: empathy, connection, power and freedom" (Brown, 2006, p.47). Viramma resists any attempt that tries to defame her community. She becomes the spokeswomen of her community that has been ridiculed with an avowal as her retort to derision intended to cause shame becomes an opportunity to reclaim agency when she says: 
It's not for nothing that people say that Pariahs are like crows, children and grown-ups alike. It's not just the colour. Like crows, we're always in a group. Like crows, we never eat alone. When a crow finds something, he calls his friends to come and share it with him: it's the same with us (Viramma, Racine \& Racine, 1997, p.5)

Viramma embraces her identity and empathizes with her community thereby exhibiting resilience. The freedom that she enjoyed within her community was replaced by restrictions in the ur. The trajectory of resilience of Viramma is like a wick of a lamp that was close to being blown away by the wind of vulnerability but still continued to burn.

Viramma empathizes with her daughter and endorses her individual choice of life partner (Viramma, Racine \& Racine, 1997, p.211), a chance that she was denied herself. As an agent of change she becomes the voice of her daughter. The older she became, greater was her voice, in speaking against norms of gender injustice. Her conviction on the need for consent within relationship is an evidence to her sense of agentic self. She articulates this as "you can't force anyone to stay or sleep with you. It's the same for all women, for you the same as me. Govinda created us all the same and no one can touch a woman unless she agrees. Between a man and a woman, both have to be willing, otherwise the man's hand will never be able to stroke anything!" (Viramma, Racine \& Racine, 1997, p.210). It must be recalled that Viramma's younger self barely resisted attempts of imposition of all kinds. She did not have a choice but to marry as a child but wields a better future for her children. The freedom of choice that she gives her daughter is a case in point.

Despite having suffered from caste virulence, Viramma still persisted, and never gave up. As she grew older, she bounced back, and reclaimed her agentic self. This act of hers can be found to have a significant difference to what caste discrimination had earlier reduced her to. She voices the presence of individual agency within her community despite the prevalent derogatory view of its women as "eh yes! Nothing happens without the woman's say so, even if she is a Paratchi!" ((Viramma, Racine \& Racine, 1997, p.209). She draws strength from her emotional resilience despite the subjection of caste identity. The transition from vulnerability to resilience is an ongoing process (Brown, 2006) which involves lesser or greater levels of exercising coping strategies. The conscious utilization of individual agency to win over situations that deter one's well-being becomes a tool for coping enabled resilience.

Vulnerability meted out by Viramma, some of which she has no control over is subsumed in the face of resilience that she exhibits. Although not significant, from the already analysed livelihood perspective, Viramma's human capital accumulation is strengthened by social capital connection which together help her receive the threats and shocks enabling her to face vulnerability. The synergy between both human and social capital together with all other elements provide Viramma with the much needed resilience. It can also be said from the visible patterns of resilience that Viramma's life is built on agency sometimes less and other times more. In other words although Viramma's life was all awash and dangled between vulnerability and susceptibility (Kottow, 2003) she failed to yield to susceptibility.

\section{Discussion}

Viramma is a victim of social stratification ${ }^{6}$ that operates in the principle of domination and subordination. In addition to this, structural inequalities of class, caste and gender do not spare her. Given the deep seated practice of caste divide that offer structural limitations, Viramma's life events operate within the caste she was born into and not outside of it. It is pertinent to recall 
Velaskar's observation "in the caste war situations today, women align with their own castes" (Velaskar, 2016, p.407). Viramma likewise offers less challenge to the existing caste divide, but tries to champion the cause for self-respect by emerging as a trusted voice of her community. She witnessed the immediacy of gender imbalance reinforced by the normative notions of patriarchy. There is also a need to take cognizance of the class divide that homogenized her community into one category of the exploited. Velaskar deplores not to give subordinate treatment to issues that are related to gender while dealing with caste and class (Velaskar, 2016, p.391). Keeping this in mind this article in addition has established the livelihood link to the caste, class and gender relations that determine any individuals' well-being for "freedom within the realm of necessity can be universalized to all; freedom from necessity can be available to only a few" (Mies \& Shiva, 2004, pg.333). In sum the victim in Viramma gets resuscitation through coping enabled resilience.

Whichever interpretative line one chooses to follow there are always a number of new ways that linkages may be forged so as to delineate and decipher meaning from the narration of lived lives. The use of sustainable livelihood framework in adaptation in this research paper is an experimental attempt in this direction. Further investigation, which will take into account the variables of vulnerability and resilience in other settings can be done so that the association between these two variables in the context of individual lived realities can be understood better.

\section{Conclusion}

Central to the imaging of Viramma's self, vulnerability and resilience branches out to be an essential axis that determine her existence. In other words, it is in the synergy between vulnerability and resilience that Viramma's life rests. The demands of caste hierarchy compel Viramma towards leading an imperilled existence to which she refused to succumb. The disquiet that arise out of Viramma's life point towards the problems of caste, class and gender oppression that it becomes important to give adequate attention to such issues which are excessively in vogue. Viramma, challenges not the gender subjectivities that are already in place; instead she traverses within its trajectory scripting her destiny out of it. There is also a need to draw parallels with other women's lives within and outside the narrative so that any narrative on lived experiences become vehicles of conscientization.

\footnotetext{
Notes

1. This claim is arrived from an analysis of the background of women whose writings appear in the collection on women's writing in English. See. Tharu, S., \& Lalita, K. (1995); John, M. E. (2008); De, S. E., \& Pereira, L. (2008) and Zaidi, Annie. (2016).

2. There are several studies and assessment reports on women and their wellbeing. Notable among all postulations is 'the feminization of poverty' that would add on to the understanding that is expressed.

3. for a comprehensive understanding on life narrative see Smith, S., \& Watson, J. (2001)

4. ceri - is the outer circle of the village and identified by the name colony. It is here that the Dalits live. It is cut from the main portion of the village where people of other castes live.

${ }^{5 .} \mathrm{ur}$ - a place where people of all communities except the dalits live. It is mostly located in and around the village heartland.
} 
6. the Indian caste system finds its presence and detailed analysis in Gupta, Dipankar. (1991), a collection of essays on different aspects of stratification. See also Quigley, D. (2002)

\section{References}

Ahmed, S. (2004). The cultural politics of emotion. New York: Routledge.

Bhandari, H., \& Yasunobu, K. (2009). What is Social Capital? A Comprehensive Review of the Concept. Asian Journal of Social Science, 37(3), 480-510. Retrieved from http://www.jstor.org.library.britishcouncil.org.in:2048/stable/23655211

Brown, B. (2006). Shame Resilience Theory: A Grounded Theory Study on Women and Shame. Families in Society. 87. 43-52. Retrieved from https://doi.org/10.1606/1044-3894.3483

Carpenter, R. (2005). "Women, Children and Other Vulnerable Groups": Gender, Strategic Frames and the Protection of Civilians as a Transnational Issue. International Studies Quarterly, 49(2), 295-334. Retrieved from http://www.jstor.org/stable/3693516

Cooley, C. H. (1902). Human nature and the social order. New York: Charles Scribner's Sons

De Haan, L. (2012). “The Livelihood Approach: A Critical Exploration”. Erdkunde, 66(4), 345-357. Retrieved from http://www.jstor.org.library.britishcouncil.org.in:2048/stable/41759104

De, S. E., \& Pereira, L. (2008). Women's voices: Selections from nineteenth and early-twentieth century Indian writing in English. New Delhi: Oxford University Press.

DFID, Department of International Development. (1999). Sustainable livelihood guidance sheets. London: DFID.

Guidry-Grimes, L., \& Victor, E. (2012). Vulnerabilities compounded by social institutions. International Journal of Feminist Approaches to Bioethics, 5(2), 126-146. doi:10.2979/intjfemappbio.5.2.126

Gupta, Dipankar. (1991). Social stratification. Delhi: Oxford University Press.

John, M. E. (2008). Women's studies in India: A reader. New Delhi: Penguin Books.

Kottow, M. H. (2003), The Vulnerable and the Susceptible. Bioethics, 17: 460-471. doi:10.1111/1467-8519.00361

Luna, F. (2009). Elucidating the Concept of Vulnerability: Layers Not Labels. International Journal of Feminist Approaches to Bioethics, 2(1), 121-139. Retrieved from http://www.jstor.org.library.britishcouncil.org.in:2048/stable/40339200

Maynes, J.M., Pierce, L.J., \& Laslett, B. (2008). Telling stories. Ithaca: Cornell University Press

Menon, N. (2012). Seeing like a feminist. New Delhi: Zubaan and Penguin Books.

Mies, M., \& Shiva,V. (2004). The subsistence perspective. In S. Harding (Ed.), Feminist standpoint theory reader (pp. 333- 337). New York: Routledge.

Quigley, D. (2002). The interpretation of caste. New Delhi: Oxford University Press.

Smith, E. Dorothy. (2004). Women's perspective as a radical critique of sociology. In S. Harding (Ed.), Feminist standpoint theory reader (pp. 21-33). New York: Routledge.

Smith, S., \& Watson, J. (2001). Reading autobiography: A guide for interpreting life narratives. Minneapolis: University of Minnesota Press.

Tharu, S., \& Lalita, K. (1995). Women writing in India 600 B.C. to the present. Delhi: Oxford University Press.

Turner, B. S. (2006). Vulnerability and human rights. Pennsylvania: The Pennsylvania State University Press. 
Velaskar, P. (2016). Theorising the interaction of caste, class and gender: A feminist sociological approach. Contributions to Indian Sociology, 5o(3), 389-414. https://doi.org/10.1177/0069966716657461

Viramma., Racine, J., \& Racine, J.-L. (1997). Viramma, life of an untouchable. London: Verso.

Zaidi, Annie. (2016). UNBOUND: 2, ooo years of indian women's writing. New Delhi: ALEPH Book Company.

\author{
About the Author \\ Jebamalar. E, is a research scholar in the Department of English, Pondicherry University, working \\ under the supervision of Dr. Binu Zachariah. A trained social worker with a literary and social \\ insight her research interests include Life Writing, Experiential narratives, Gendered practices \\ and also creation of innovative, experimental linkages between the humanities and social \\ sciences.
}

